\title{
Manufacturing Industry Transformation and Upgrading Based on Industrial Agglomeration Analysis of Productive Service
}

\author{
- Case Study of Quanzhou City \\ Yingyi HUANG, Xuhong XU* \\ TSL School of Business \\ Quanzhou Normal University \\ Quanzhou, China \\ tutorxuxuhong@163.com
}

\begin{abstract}
At present, the manufacturing industry is facing the severe development challenge of transformation and upgrading, and the solution of the problem depends largely on the development of production service. Therefore, this paper constructs a static panel data regression model based on location entropy and spatial Gini coefficient, and analyzes the agglomeration effect of production service industry on the transformation and upgrading of manufacturing industry in Quanzhou city. The results show that the agglomeration of production service industry plays a strong role in promoting the transformation and upgrading of manufacturing industry. The contribution of this study may provide both the theoretical reference and support for the transformation and upgrading of the manufacturing industry.
\end{abstract}

Keywords-Manufacturing Industry; Production Service; Agglomeration; Transformation and Upgrading; Quanzhou city

\section{INTRODUCTION}

Manufacturing industry is the foundation and pillar industry of national economy. It boosts rapid growth of nation economy and technology development that no other industry can replace. It is a significant parameter to measure national economic strength and international competitiveness for its development. Until 2016, Chinese entire manufacturing industry added value is 24,786 billion RMB. China has become the country with the highest manufacturing industry output value all over the world. In spite of this large scale of industry, most of products are still in a low stream of international industry chain. Current overall development status is also in a relatively backward position comparing with other advanced manufacturing industry level of developed regions. Moreover, due to international economy crisis and impact of domestic economic downturn in decades, China's traditional manufacturing industry faces a severe challenge. How to maintain a steady growth speed and meanwhile promote the upgrade of manufacturing industry to achieve sustainable development is a present priority issue. Some research reveals that the industrial agglomeration can enhance not only relevant technical level, labor productivity, but also promote industrial upgrading and competitiveness [1-3]. As an important matching industry of manufacturing, producer services industry, appears throughout each parts of production manufacturing. Its agglomeration development provokes manufacturing enterprises to optimize resources allocation and enhance productivity as well. Moreover, promotes domestic manufacturing industry to realize transformation and upgrading [4,5]. At present, through analysis of input-output relationships, simultaneous measurement equations and panel data model, research in domestic and abroad studies the interaction between development of producer services and manufacturing industry, as well as agglomeration features and influence factors of producer services industry [6-10]. However, most exploratory and confirmatory researches are focus on the interaction between producer services and manufacturing industry [11]. In addition, the mechanism of how productive service industry transforms and upgrades manufacturing industry is not only embodied in geographic centralization, but also deeply influenced by modern service supporting system, which based on research and development design, finance, modern logistics, and talent support. Therefore, the paper chooses Quanzhou city as the research sample, and analyses how the industrial agglomeration effect of producer service industry influences the transformation and updating issue of manufacturing industry in this city.

Quanzhou city is located at the southeast coast of China and along the Taiwan Strait. The city is well-known as 'Quanzhou experience' and 'Quanzhou model'. There are 5 huge industrial clusters over hundred-billion RMB such as textile and garment, footwear, petrochemical, machinery and equipment, building materials. Quanzhou city has 154 China famous brands, ranking the first place in the national prefecture-level cities; and 733 international registered trademarks, ranking the third place in the national prefecturelevel cities. There are 42 brands worth over 100 million RMB. By 2016, Quanzhou's GDP had reached 664.6 billion RMB, and always been ranked first in Fujian province in the past 18 years. Among them, the scale of industrial added value had achieved 305.259 billion RMB, and meanwhile increased 7.7\% compared with the same period last year. The employee number of manufacturing industry had also reached 2.4 million. There were 2308 enterprises' value over 1 hundred 
million RMB, and 189 enterprises' value over 1 billion RMB. Quanzhou city has been selected as the first local model city for 'China made 2025'. It can be seen that Quanzhou has established a huge manufacturing system and become one of the important cities in the development of equipment manufacturing industry in China.

The other parts of this paper are structured as follows: the mechanism analysis on productive services agglomeration on transformation and upgrading of manufacturing industry is performed in section 2, the empirical analysis on Quanzhou city is provided in section 3 , and the conclusions and policy suggestions from the research achievements are discussed and summarized in section 4 .

\section{MECHANISM ANALYSIS ON PRODUCTIVE SERVICES} AGGLOMERATION ON TRANSFORMATION AND UPGRADING OF MANUFACTURING INDUSTRY

\section{A. Analysis of the impact factors}

Productive service industry is the element of knowledge intensive of manufacturing industry, and it is also the basis and guarantee on the improvement of manufacturing productivity. Developed productive service is the necessary prerequisites and basis for the formation of a competitive manufacturing sector. In the actual production, those two aspects show a dynamic interaction relation of mutual dependence, interaction and common development. The mechanism is shown below as Fig. 1.

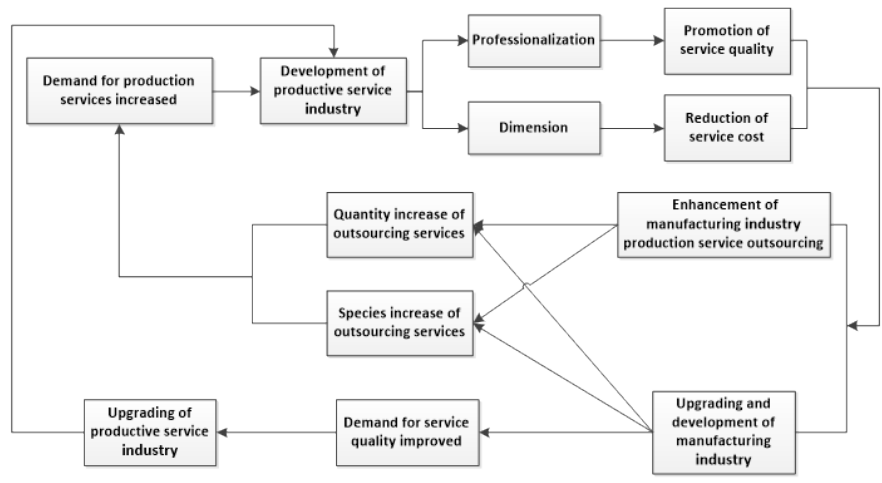

Fig. 1. The interactive relationships between manufacturing industry and production service industry

As shown in Fig. 1, with the expansion of manufacturing industry and increase of outsourcing services, demand of different productive service will increase, which prompts the development of productive services industry to be more specialized and scaled, thus reduce service costs, improve service quality; indirectly promote development of manufacturing productivity, forming a benign loop ecology circle of interdependence and interaction.

Industrial agglomeration is a process where the same industry is highly concentrated in a particular geographical region, and industrial capital factors converge in the space. Although there are a large number of small and medium-sized manufacturing enterprises in Quanzhou city, most of them are small, and the similarity in the products is very high, and the technical content is low. It is easy to cause the shortcomings like redundant construction, vicious price competition among enterprises. The agglomeration development of productive services industry promotes the formation of industrial chain matching the development of upstream, midstream and downstream products of manufacturing, and forms industrial agglomeration effects such as resource sharing and complementary advantages. In addition, the agglomeration matching service industry could strengthen trust and cooperation between enterprises, and could also establish service platforms such as risk investment, public information, network marketing, financing guarantee, intellectual property protection, incubator according to requirement from manufacturing industry, provide a full range of products supply and services, realize the seamless joint between productive services industry and manufacturing industry.

\section{B. The measurement of production service industry agglomeration}

Industrial agglomeration has a dual attribute. From the industry perspective, it's the uneven distribution of a certain industry in the country. In addition, from a regional perspective, it can be regarded as that a large number of enterprises of a certain industry have got together in a certain region. So the measurements and performance of the industrial agglomeration are different form different perspectives. At present, there are many methods and measurements to measure the agglomeration level of a certain industry, such as common concentration index, location entropy, spatial Gini coefficient and Herfindal index. Because the data availability and measurement accuracy are relatively high, location entropy is more used to analyze and measure the industrial agglomeration level of a certain region. The formula of location entropy is as follows:

$$
L Q_{i j t}=\frac{e_{i j t} / \sum_{j} e_{i j t}}{e_{j t} / \sum_{j} e_{j t}}
$$

Where, $L Q_{\mathrm{ijt}}$ is location entropy of industry $j$ in region $i$ at time $t, e_{\mathrm{ijt}}$ is the number of employees of industry $j$ in region $i$, $e_{\mathrm{jt}}$ is the number of employees of industry $j$ over the country at time $t . \sum_{j} e_{i j t}$ is the total number of employees of all industries in region $i$ at time $t . \sum_{j} e_{j t}$ is the total number of employees of all industries over the country at time $t$.

However, if only from the industry or regional perspective, it's difficult to reflect the trend of industrial agglomeration veritably and preferably. Spatial Gini coefficient uses the sum of the regions to represent the degree of industrial agglomeration, which can reflect the agglomeration level of a certain industry in the country more comprehensively. The formula of spatial Gini coefficient is as follows:

$$
G_{i j}=\sum_{i}\left(s_{i j}-x_{i}\right)^{2}
$$

Where, $G_{i j}$ is Gini coefficient of industry $j$ in region $\underline{i}$. $s_{\mathrm{ij}}$ is the ratio of the number of employees of industry $j$ in region $i$ to the number of employees of industry $j$ over the country. $x_{\mathrm{i}}$ is 
the ratio of the total number of employees of all industries in region $i$ to the total number of employees of all industries over the country. $0<G_{i j}<1$, the bigger $G_{i j}$ is, the higher the agglomeration level of industry $j$ in region $i$ is.

\section{EMPIRICAL ANALYSIS}

In this paper, the empirical research is based on the production of service-related data about the districts, counties and cities in Quanzhou city from 2011 to 2015. Based on the agglomeration of production service industry, the impact on the transformation of manufacturing industry is analyzed from three dimensions: industrial agglomeration, urbanization level and knowledge spillovers. The relevant data is from 'Quanzhou Statistical Manual' and 'China Statistical Yearbook’, as shown in Table 1.

TABLE I. RELEVANT ST ATISTICS

\begin{tabular}{|c|c|c|c|c|}
\hline Year & $\begin{array}{c}\text { Investment in } \\
\text { fixed assets } \\
\text { (Billion RMB) }\end{array}$ & $\begin{array}{c}\text { Number of } \\
\text { college teachers } \\
\text { perten thousand } \\
\text { people }\end{array}$ & $\begin{array}{c}\text { Industrial output } \\
\text { value (Billion } \\
\text { RMB) }\end{array}$ & $\begin{array}{c}\text { Number of } \\
\text { industrial } \\
\text { employment } \\
\text { (Million people) }\end{array}$ \\
\hline 2011 & 69.20 & 88 & 900.0 & 1.75 \\
2012 & 156.8 & 87 & 950.1 & 1.76 \\
2013 & 185.8 & 87 & 1059.0 & 1.65 \\
2014 & 209.8 & 88 & 1201.1 & 1.61 \\
2015 & 272.5 & 89 & 1241.8 & 1.17 \\
\hline
\end{tabular}

\section{A. Indicators and models}

Industrial competitiveness is the key factor affecting the industrial upgrading, and the strength of competitiveness directly reflects the status and extent of industrial upgrading. One of the most important indicators of industrial competitiveness is the labor productivity. In this paper, the labor productivity of the manufacturing industry is used to measure the level of transformation and upgrading of the manufacturing industry. In addition, in order to avoid the autocorrelation between data, this paper chooses the relevant indexes based on the above three dimensions, and carries on the logarithmic processing to each index, and then constructs a static panel data model:

$$
\text { LnManu }_{i}=c+\beta_{1} \operatorname{LnAggl}_{i}+\beta_{2} \text { LnScie }_{i}+\beta_{3} \text { LnSpil }_{i}+\Delta_{i}
$$

Where, $c$ is a constant term, $\beta_{1}, \beta_{2}, \beta_{3}$ are the variable term, and $\Delta_{i}$ is the error term. $M a n u_{\mathrm{i}}$ represents the manufacturing productivity of the $i$-th city. The ratio of the industrial output value of the $i$-th city to the number of industrial employment in the city is used as a measure of the ability of the manufacturing industry to transform and upgrade. Aggl $_{i}$ represents the level of production service agglomeration in the $i$-th city. Scie $_{\mathrm{i}}$ is the technical input of the $i$-th city, which is used by quantifying the investment in $\mathrm{R} \& \mathrm{D}$ of the manufacturing industry in each year. Because the city's statistical yearbook is not subdivided into the industry research and development investment, this paper uses the fixed assets investment instead of the investment in research and development. Spil $_{\mathrm{i}}$ represents the knowledge spill of the $i-$ th city, which is ratio of the number of full-time teachers in the university among ten thousand people in this city to the national average.

In addition, according to Section II, we can know that the two aggregation measures have their own merits, and they are widely used in industrial agglomeration measurement. In order to reflect the concentration of an industry more reasonably and more comprehensively, the paper proposes the following weighting indicators:

$$
\operatorname{Aggl}_{i}=\gamma L Q_{i}+(1-\gamma) G_{i}
$$

Where $\gamma$ is the index weight, $\gamma \in(0,1)$. The agglomeration level $\left(\mathrm{Aggl}_{i}\right)$ in the $i$-th city is measured by the location entropy $L Q_{i}$ and the spatial Gini coefficient $G_{i}$. The higher the $\mathrm{Aggl}_{i}$ is, the higher the level of production service agglomeration is. On the contrary, the smaller the Aggli is, the lower the level is. Then the data model (4) is transformed into model (5).

LnManu $_{i}=c+\beta_{1} \operatorname{Ln}\left[\gamma L Q_{i}+(1-\gamma) G_{i}\right]+\beta_{2} \operatorname{LnScie}_{i}+\beta_{3} \operatorname{LnSpil}_{i}+\Delta_{i}$

\section{B. Results and analysis}

In this paper, the correlation and regression analysis is made for model (5) by using Eview7.0, the results are presented as follows.

1) Correlation analysis: As shown in Fig. 2, the manufacturing industry is closely related to 3 dimensions, such as agglomeration of productive service industry, urbanization level and knowledge spillover. Among them, the correlation index of manufacturing industry and agglomeration of productive service industry reached 0.8 . It shows that the agglomeration of productive service industry has a great influence on the manufacturing industry. In addition, the correlation index of manufacturing industry and investment in technology research and development (that is $\mathrm{Scie}_{\mathrm{i}}$ ) reached 0.88 , indicating that technology research and development has a very important role in promoting transformation and upgrading of the manufacturing industry.

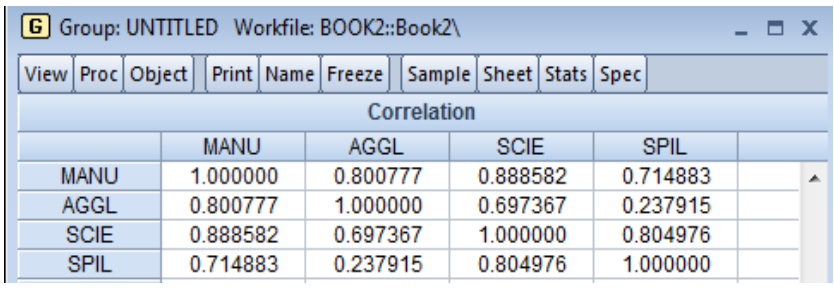

Fig. 2. Correlation analysis

2) Regression analysis: From the results of Fig. 3, it can be seen that the effect of agglomeration of productive service industry on the transformation and upgrading of manufacturing industry is positive, and the influence coefficient is 2.94. That is every improvement in a unit of agglomeration of productive service industry will increase 2.94 pre-unit in manufacturing industry. This shows that the agglomeration of productive service industry has a strong role in promoting transformation and upgrading of the manufacturing industry. 
This is mainly due to the agglomeration effect of productive service industry reduce the cost of their own. In addition, the competition effect forces the productive service industry to reduce the price of services, strengthen the innovation and improve the quality of service. This helps the manufacturing industry to save the intermediate service cost to some extent, and directly reduces the input cost of manufacturing outsourcing. It shows that the agglomeration of productive service industry has effectively promoted transformation and upgrading of the manufacturing sector.

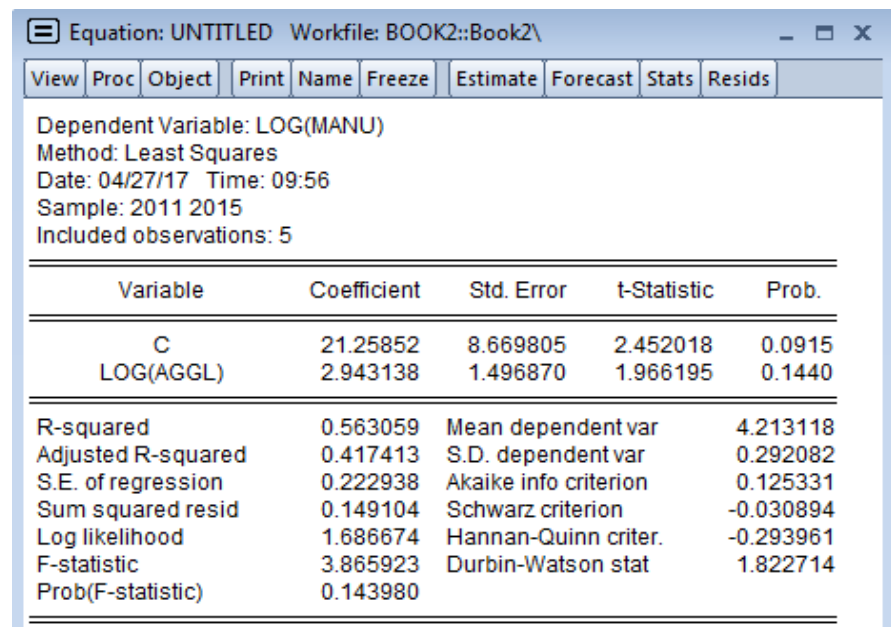

Fig. 3. Regression analysis

\section{Conclusions}

This paper has focused on the transformation and upgrading of the manufacturing industry under the agglomeration analysis of production services industry in Quanzhou city. The empirical analysis shows that the correlation index between manufacturing and producer services is over 0.8. Meanwhile, for production services industry under the agglomeration, per-unit increases the efficiency of the manufacturing sector by 3 units. Therefore, the agglomeration of production services industry plays a strong role in promoting the transformation and upgrading of manufacturing industry.

Based on the above results, the following policy recommendations are proposed. First, the government at all different levels should grasp the critical point of agglomeration production services industry based on the regional and city industrial environment and characteristics in order to promote the transformation and upgrading of the manufacturing sector. Secondly, active and effective guarantee policies should be implemented to provide all external impetus for the practice of the agglomeration of production services industry.

\section{ACKNOWLEDGMENT}

This work is partially supported by the Natural Science Foundation of Fujian Province for Youths, China (grant No. 2017J05116), the Natural Science Foundation of Fujian Province, China (grant No. 2015J01286), the JK class project in Fujian Province Department of Education (grant No. JK2014037), the Education Research Project of Fujian Province for Young and Middle-aged Teacher (grant No. JAS150448). We deeply appreciate the organizations mentioned above.

\section{REFERENCES}

[1] K Desmet, and M Fafchamps, "Changes in the spatial concentration of employment across US counties: a sectoral analysis 1972-2000”, Journal of Economic Geography, vol.5, no.3, pp. 261-284, 2005.

[2] A Macpherson, "Producer services linkages and industrial innovation: results of a twelve-year tracking study of New York State manufacturers”, Growth \& Change, vol.39, no.1, pp. 1-23, 2008.

[3] J.C Xia, and X.B Zhang, "A study on the basic path for producer services to promote industrial upgrading and the related finance and taxation measures”, China Finance and Economic Review, no.4, pp. 111, 2014.

[4] J.R Markusen, "Trade in producer services and other specialized intermediate inputs”, American Economic Reviw, vol.79, no.1, pp. 34-42, 1989.

[5] K Eswarn, "The role of the service sector in the process of industrializations”, Journal of development economics, vol.68, no.2, pp. 401-420, 2002.

[6] T.W Feng,"The relationship between producer service and manufacturing efficiency", The Journal of Quantitative \& Technical Economics, no.3, pp. 56-65, 2009.

[7] R Franke, and P Kalmbach, "Structural change in the manufacturing sector and its impact on business-ralated services: an input-output study for Germany”, Structural Change and Economic Dynamics, vol.16, no.4, pp. 467-488, 2005.

[8] M Anderson, "Co-location of manufacturing \& producer services: a simultaneous equation approach”, CESIS Electronic Working Paper Series Paper, No.8, 2004.

[9] D Grimes, "Change in the concentration of employment in computer services: spatial estimation at the U.S. Metro country level”, Growth and Change, vol.38, no.1, pp. 39-55, 2007.

[10] S.R Meyer, "Finance insurance and real estate firms and the nature of agglomeration advantage across Canada and within metropolitan Toronto", Canadian Journal of Urban Research, vol.16, no.2, pp. 149181, 2007.

[11] S.H Pakr, and K.S Chan, "A cross country input-output analysis of intersectoarl relationshios between manufacturing and service and their emp loyment implications”, World Development, no.2, pp. 199-212, 1989. 